\title{
Letters to the Editor-August 3, 2020
}

\author{
Physicists returning to the lab after the long shutdown describe the odd \\ feeling of being back and a new appreciation for the social aspect of \\ science.
}

$\square$ o you have a story to share about your experience with labs re-opening during the pandemic? Write to physics@aps.org. A selection of letters will be posted in Physics and APS News.

\section{Testing Ideas After Months of Thinking}

When Madrid announced its lockdown, I had just traveled to Germany to visit my family. Instead of returning to Spain, I stayed with my brother so that we could motivate one another during the seemingly endless home-office odyssey. During those months away from my lab-intensive project, I had the rare opportunity to devote time to exploring the scientific literature. As a result, I came up with out-of-the-box ideas that I look forward to testing.

Now l'm back in Madrid, and being in the lab brings mixed feelings. We're able to perform our experiments without substantial constraints, which is great. However, we're constantly reminded of the real danger of the virus. We must

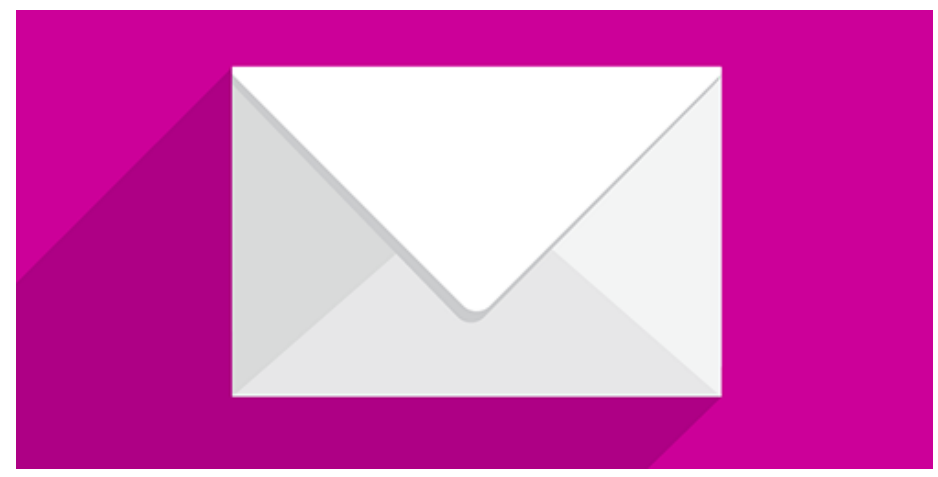

Credit: APS/Carin Cain wear masks at all times except when eating and drinking. This requirement can get wearisome in Madrid's intense summer heat. Furthermore, social contact within the institute has been reduced to a minimum, which makes the work experience a rather lonely one. Still, I realize I'm one of the lucky few to not be drastically affected by this hard time. And I've even been able to take something positive out of it.

- Richard Schaufele is a Ph.D. student studying multifunctional nanocomposites at the IMDEA Materials Institute in Spain.

\section{New Data is Trickling In}

My postdoc, Yu Gao, was growing sorghum-a plant being engineered for use in biofuels-in a ${ }^{13} \mathrm{CO}_{2}$-rich environment when the shelter-in-place orders hit the Bay Area. Luckily, we were given special permission to complete the growth cycle. With the help of a camera, we could remotely monitor gas levels in the growth chamber. And we could come in as necessary to check on the plants until they were ready for harvest.

Working with our collaborator who studies the plants with NMR at the Environmental Molecular Sciences Laboratory (EMSL) has taken a lot of coordination because he's in another state (Washington). He let us know when he could partially return to the lab to receive cold packages. And, once we got the green light, a colleague who had access to our institute's labs shipped our box of precious samples. We're now collecting data! Our next challenge is getting enough time in the lab here to generate the next set of samples.

- Jenny Mortimer is a research scientist in Biological Systems \& Engineering and Director of Plant Systems Biology at the Joint BioEnergy Institute in Berkeley, California. 


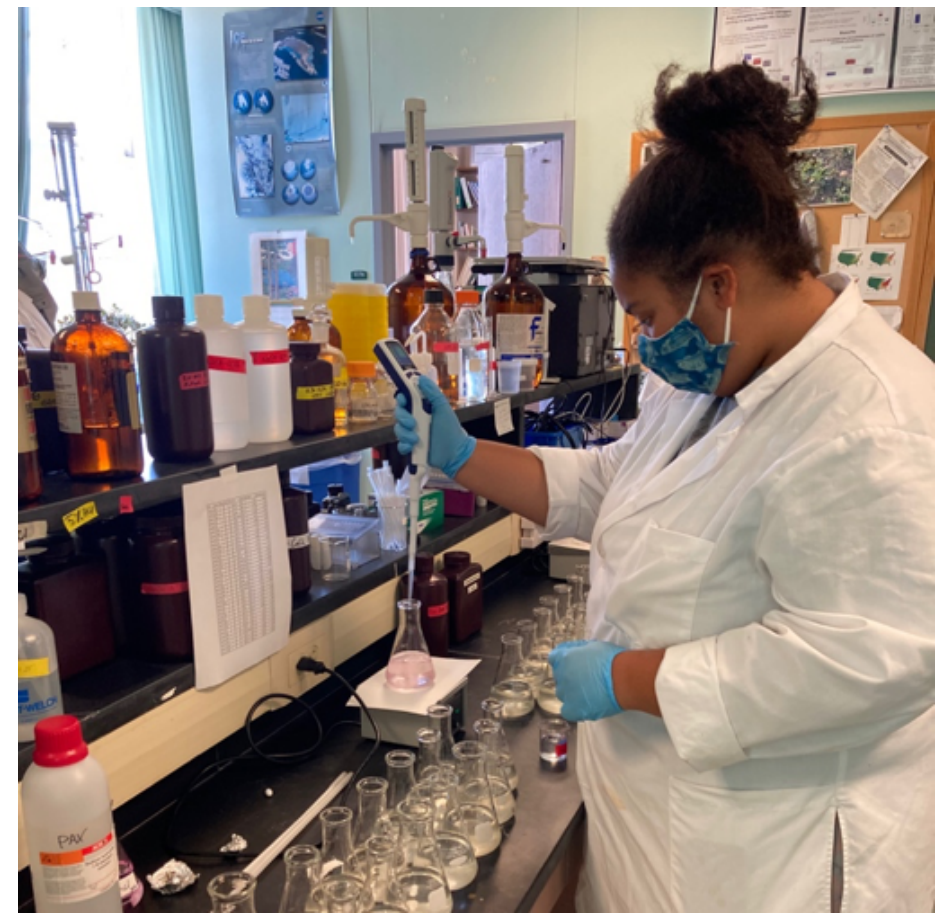

Georgia Hilliard, an undergraduate student, performing titrations to analyze the aluminum content of soil.

Credit: J. DeForest/Ohio University

\section{Functional Work, but Few Informal Interactions}

My laboratory reopened four weeks ago for some experimental work, but most people have not returned to the offices and classrooms. It's good to be back: Replacing experiments with numerical work during lockdown wasn't the same. I've quickly gotten used to the lab's new safety procedures. Fortunately, my experiments are small scale and carry few particular risks. Still, most interactions remain restricted to emails and video conferences. The loss of countless informal interactions is acutely felt.

- Merlin Etzold is a research fellow in the Environmental and Industrial Fluid Dynamics group, Department of Applied Mathematics and Theoretical Physics at the University of Cambridge in the UK.

\section{Extra Caution and More Disinfectant in the Field}

Conducting science in a pandemic world has been challenging, but progress nevertheless continues. Every year in late June for the last decade, my students and I have performed the same data gathering tasks at my outdoor site that allows for long-term soil manipulation. The procedures and order of tasks are almost ritualistic, which allows us to maintain consistency throughout the years. This year, I had to write up a COVID-19 safety plan [for the field work] that involved extra caution and more disinfectant. What normally is a 10-hour day turned into an 11- to 12-hour day. I also didn't anticipate, or even recognize before, how much conducting science is a social endeavor. Putting on gloves was normal and wearing a mask was easy, but social distancing created new challenges, especially when trying to train the next generation of scientists.

\section{- Jared DeForest is an Associate Professor of Ecosystem Ecology} at Ohio University. 